\title{
Comparison of 2-week and 1-year protocol renal allograft biopsies regarding technical feasibility and clinical outcomes
}

\author{
Manuel Lim, Kyo Won Lee
}

Department of Surgery-Transplantation, Samsung Medical Center, Seoul, Korea

Background: Renal allograft biopsy improves early detection and treatment of subclinical rejection. Still, there are rare reports about the outcomes of 2-week protocol biopsy. To compare 2-week and 1-year biopsies in terms of technical feasibility and clinical outcomes.

Methods: A total of 916 renal allograft biopsies were performed in adult recipients between 2012 and 2019. Two-week and 1-year biopsies were guided with ultrasound in 882 and 556 patients, respectively. These protocol biopsies were compared in terms of technical feasibility and clinical outcomes. Standard references were clinical-laboratory findings and biopsy examinations. Non-inferiority test and univariate analysis were used for statistical analysis.

Results: There were no significant differences regarding baseline characteristics between the 2-week and 1-year biopsies. All allograft biopsies were technically successful. Major complication (Clavien-Dindo grading III-IV) rates of 2-week and 1-year biopsies were $0.23 \%(2 / 882)$ and $0.18 \%(1 / 556)(P=0.645)$. On non-inferiority analysis, the major complication rate of 2-week biopsy was not inferior to that of 1-year biopsy. Univariate analysis showed that delayed graft function, pre-biopsy platelet $<100 \mathrm{~K}$, pre-biopsy creatinine $\geq 2.0 \mathrm{mg} / \mathrm{dL}$ and pre-biopsy blood urea nitrogen (BUN) $\geq 40 \mathrm{mg} / \mathrm{dL}$ were associated with major complications in 2-week biopsy.

Conclusions: Two-week biopsy as well as 1-year biopsy is technically feasible and safe. Prior to biopsy, platelet, creatinine, and BUN should be carefully checked to predict major complication.

Corresponding author: Kyo Won Lee

E-mail: kw1980.lee@gmail.com

(c) The Korean Society for Transplantation

This is an Open Access article distributed under the terms of the Creative Commons Attribution Non-Commercial License (http://creativecommons.org/licenses/by-nc/4.0/) which permits unrestricted non-commercial use, distribution, and reproduction in any medium, provided the original work is properly cited. 